Revue d'histoire de l'Amérique française

BEVUE D.HISTOIRE DE L'AMÉRIQUE FRANÇAISE

Conseil des travailleuses et travailleurs du Montréal métropolitain, Cent ans de solidarité. Histoire du CTM 1886-1986. Montréal, VLB Éditeur, 1987. 150 p. 29,90 \$

Jean-François Cardin

Volume 41, numéro 4, printemps 1988

URI : https://id.erudit.org/iderudit/304629ar

DOI : https://doi.org/10.7202/304629ar

Aller au sommaire du numéro

Éditeur(s)

Institut d'histoire de l'Amérique française

\title{
ISSN
}

0035-2357 (imprimé)

1492-1383 (numérique)

Découvrir la revue

Citer ce compte rendu

Cardin, J.-F. (1988). Compte rendu de [Conseil des travailleuses et travailleurs du Montréal métropolitain, Cent ans de solidarité. Histoire du CTM 1886-1986. Montréal, VLB Éditeur, 1987. 150 p. 29,90 \$]. Revue d'histoire de l'Amérique

française, 41(4), 616-617. https://doi.org/10.7202/304629ar d'utilisation que vous pouvez consulter en ligne.

https://apropos.erudit.org/fr/usagers/politique-dutilisation/ 


\section{CONSEIL DES TRAVAILLEUSES ET TRAVAILLEURS DU MONTRÉAL MÉTROPOLITAIN, Cent ans de solidarité. Histoire du CTM 1886-1986. Montréal, VLB Éditeur, 1987. 150 p. 29,90\$}

Afin de souligner le centenaire et leur organisation, les responsables du CTM publiaient l'an dernier une petite monographie retraçant l'histoire du Conseil. Rassurez-vous, nous n'avons pas affaire ici à un «album-souvenir», mais bien à un travail sérieux, basé notamment sur le dépouillement des archives relativement riches du CTM. Financée en partie par les programmes d'Emploi et Immigration Canada, la recherche fut menée par une équipe de jeunes historiens de formation universitaire. Sylvie Murray et Élyse Tremblay ont assuré la rédaction finale du texte.

L'ouvrage se compose de six chapitres chronologiques au début desquels les auteurs situent rapidement le contexte social et syndical plus général dans lequel le Conseil aura à évoluer. À ce découpage chronologique conventionnel viennent se superposer des analyses thématiques portant sur des sujets qui, bien que considérés sur l'ensemble des cent ans, sont jumelés à la période où ils prennent une importance particulière. Par exemple, les auteurs ont traité entièrement le thème de l'action politique au chapitre deux, consacré aux trente premières années du siècle, période où cette question soulève de vifs débats au sein du Conseil des métiers. Tour à tour sont ainsi abordées les questions suivantes: la raison d'être et les objectifs fondamentaux du Conseil et de ses ancêtres, l'action politique, la lutte pour l'amélioration des conditions de travail, l'organisation syndicale, la promotion des droits et libertés, la revendication de mesures sociales plus justes et l'éducation. Les auteurs relatent l'évolution de chacune de ces questions et montrent comment le Conseil les a continuellement réorientées et reformulées pour les adapter à la conjoncture changeante. Ces sections thématiques, expliquées simplement et appuyées de nombreuses citations, confèrent selon nous à l'ouvrage son intérêt premier.

Il serait fastidieux de résumer linéairement chacun des chapitres et leurs parties thématiques. Au fil des chapitres, on ne peut que remarquer à quel point le Conseil et ses ancêtres ont évolué au diapason du mouvement syndical québécois tout entier, dont ils se font l'écho fidèle des passions et des enjeux. L'histoire du CTM, c'est aussi une histoire en miniature du syndicalisme au Québec. Ainsi, au premier chapitre, les auteurs démêlent pour nous la généalogie particulièrement complexe du CTM, qui évolue en parallèle avec celle du mouvement syndical québécois et canadien, subissant les mêmes divisions entre tendances nationale et internationale au début du siècle, puis entre pratiques industrielle et de métier durant l'après-guerre. À la fin des années 1950, bien que cela se fit plus difficilement qu'aux autres niveaux, on assistera sur la scène montréalaise à la grande réconciliation des deux frères ennemis de la FAT et du COI et à la création du CTM actuel.

Entre le premier Conseil central des métiers et du travail de Montréal, né en janvier 1886 de la jonction des Chevaliers du travail et des syndicats de 
métiers de la ville, et l'actuel Conseil des travailleuses et travailleurs du Montréal métropolitain, il y a, selon les auteurs, une même raison d'être, un même projet fondamental, soit celui de constituer «un lieu de rencontre où s'unissent les forces syndicales pour la défense et l'amélioration de la condition ouvrière». En tant que groupe de pression guidé par un indéfectible parti-pris en faveur des ouvriers, des démunis et du monde ordinaire, le CTM est en effet de toutes les luttes, de toutes les revendications pour l'amélioration des conditions de vie et de travail, tant dans les lieux de travail qu'à l'extérieur. Toutefois, on reste parfois agacé par le point de vue nettement positiviste des auteurs, pour qui l'évolution du CTM semble être une longue et indéfectible marche vers le progrès, que représenterait l'époque actuelle, et à travers laquelle la plupart des revendications (notamment en matière sociale, de conditions de travail et d'unité syndicale) semblent arriver à un aboutissement heureux.

D'autre part, Cent ans de solidarité a les faiblesses propres à une histoire «officielle». Le texte, qui se voulait simple et accessible, est parfois fade et par trop descriptif. L'analyse est trop souvent rudimentaire, voire même parfois déficiente, et c'est en vain qu'on y chercherait un cadre plus global d'analyse qui aurait pu donner un sens à la démonstration et dynamiser davantage le récit. De même, on a évité systématiquement toute controverse, toute prise de position tranchée, tout point de vue critique, qui aurait pu créer quelque malaise ou réveiller quelque ancienne passion parmi les militants actuels, notamment quant au caractère nettement conservateur du Conseil des métiers ou à la peu reluisante chasse aux sorcières au sein des deux conseils au tournant des années 1950. Mais, encore là, ces faiblesses sont davantage dues, selon nous, à la nature même du projet, plus qu'à une carence des auteurs pour qui il fut sans doute parfois difficile de plaire à tous et à chacun.

En terminant, on se doit de souligner la présentation graphique attrayante de l'ouvrage. Le texte, réparti sur deux étroites colonnes, se lit facilement et permet l'exploitation des marges où l'on retrouve, en plus des notes habituelles, une foule de renseignements des plus divers qui enrichissent notre lecture (résumés de grèves marquantes, courtes biographies, nombreuses photos, etc.). Des tableaux synchroniques et une bibliographie complètent le tout. 